Pesq. Vet. Bras. 36(9):893-900, setembro 2016 DOI: 10.1590/S0100-736X2016000900016

\title{
Descrição morfológica dos ovários do peixe Melanotaenia boesemani em atividade reprodutiva ${ }^{1}$
}

\author{
Marcella C. Radael ${ }^{2 *}$, Paulo J. Fosse ${ }^{3}$, Rafaele M. da Silva², João C. Fosse Filho², \\ Dalcio R. de Andrade ${ }^{2}$ e Manuel V. Vidal Junior ${ }^{2}$
}

\begin{abstract}
Radael M.C., Fosse P.J., Silva R.M., Fosse Filho J.C., Andrade D.R. \& Vidal Junior M.V. 2016. [Morphological description of Melanotaenia boesemani ovaries in reproductive activity.] Descrição morfológica dos ovários do peixe Melanotaenia boesemani em atividade reprodutiva. Pesquisa Veterinária Brasileira 36(9):893-900. Centro de Ciências e Tecnologias Agropecuárias, Laboratório de Bioensaios em Piscicultura Intensiva, Centro de Ciências e Tecnologias Agropecuárias, Universidade Estadual do Norte Fluminense Darcy Ribeiro, Sala 112, Avenida Alberto Lamego 2000, Parque Califórnia, Campos dos Goytacazes, RJ 28013-620, Brazil. E-mail: marcellaradael@yahoo.com.br

The germinal ovarian tissue of the fish Melanotaenia boesemani was studied. By means of morphological analyses of the gonads, performed after the manufacture of histological slides made of paraffin and stained with hematoxylin-eosin, the cell types found were described and the rank of the maturity stage of the fishes was executed. Macroscopically was found that the species has only one ovary, rounded and in the observed phase yellowish, located in the lateral front part of the coelomic cavity. The observed females were classified in the gonadal development scale as mature/in reproduction. The presence of empty follicles and spawning marks on ovigerous lamellae proved to be evident. In vitellogenic oocytes of this fish, the presence of filaments of oocyte adhesion anchored to the pellucida zona was found. The ovaries showed general morphological appearance similar to that of other teleost fishes. Its spawning type was classified as intermittent and the pattern of development of oocytes as asynchronous.
\end{abstract}

INDEX TERMS: Melanotaenia boesemani, oogenesis, fish, ovarian histology, gonadal development, reproduction.

RESUMO.- Estudou-se o tecido germinativo ovariano do peixe Melanotaenia boesemani. Por meio de análises morfológicas das gônadas, realizadas após a confecção de lâminas histológicas elaboradas em parafina e coradas com hematoxilina-eosina, foram descritos os tipos celulares encontrados e realizada a classificação do estádio de maturidade dos peixes. Macroscopicamente, foi identificado que a referida espécie possui ovário único, arredondado e, na fase observada, amarelado, localizado na parte látero-anterior da cavidade celomática. As fêmeas analisadas foram classificadas na escala de desenvolvimento gonadal como maduro/em reprodução. A presença

\footnotetext{
${ }^{1}$ Recebido em 15 de setembro de 2015.

Aceito para publicação em 7 de abril de 2016.

${ }^{2}$ Centro de Ciências e Tecnologias Agropecuárias (CCTA), Universidade Estadual do Norte Fluminense Darcy Ribeiro, Sala 112, Avenida Alberto Lamego 2000, Parque Califórnia, Campos dos Goytacazes, RJ 28013-620, Brasil. *Autor para correspondência: marcellaradael@yahoo.com.br

${ }^{3}$ Instituto Federal do Espírito Santo, Campus Alegre, Rodovia BR 482, Km 47 s/n, Rive, Alegre, ES 29520-000, Brasil.
}

de folículos vazios e marcas de desova nas lamelas ovulígeras mostrou-se evidente. Nos ovócitos vitelogênicos deste peixe, foi constatada a presença de filamentos de adesão ovocitária ancorados à zona pelúcida. Os ovários apresentaram aspecto morfológico geral semelhante ao de outros peixes teleósteos. Seu tipo de desova foi classificado como intermitente e o padrão de desenvolvimento de ovócitos, como assincrônico.

TERMOS DE INDEXAÇÃO: Melanotaenia boesemani, peixe, oogênese, histologia ovariana, desenvolvimento gonadal, reprodução.

\section{INTRODUÇÃO}

Melanotaenia boesemani é um peixe muito utilizado no aquarismo. É originária do lago Ayamaru, na Indonésia (Kadarusman et al. 2010). São peixes bentopelágicos de água doce cuja faixa de $\mathrm{pH}$ ideal para sobrevivência está entre 6,0 a 8,0. Esses peixes pertencem à classe dos Actinopterygii (peixes com raios nas nadadeiras), ordem Atheriniformes (Fishbase 2015). 
São animais com acentuado dimorfismo sexual. Os machos se distinguem das fêmeas por apresentar coloração na parte frontal da cabeça e pelo corpo em cinza azulado brilhante; nas nadadeiras e na metade posterior do corpo apresentam coloração laranja-avermelhado e os raios da sua nadadeira dorsal são mais compridos e alongados. As fêmeas exibem uma ampla faixa lateral escura acompanhada de uma série de listras longitudinais estreitas amarelas ou laranja-avermelhado, variando de acordo com o ambiente e estado fisiológico do animal. 0 seu corpo é, em geral, mais longilíneo e com as bordas mais arredondadas que nos machos (Rainbowfish 2015).

Desde sua introdução no aquarismo, que segundo registros iniciou-se após uma expedição em novembro de 1982, M. boesemani tem se tornado mais conhecida e, hoje, pode ser considerada como o rainbowfish mais popular neste hobby (Rainbowfish 2015).

0 desenvolvimento das gônadas em $M$. boesemani já é evidente em espécimes do sexo feminino com apenas $3,4 \mathrm{~cm}$ e em peixes acima de $4 \mathrm{~cm}$ o sistema reprodutor já parece ser totalmente funcional (Fishbase. Melanotaenia boesemani Allen \& Cross, 1980).

Os ovos destes peixes apresentam adesividade, ficando fixados ao substrato utilizado para desova, essa adesão ocorre por meio de filamentos de fixação presentes no córion (Humphrey et al. 2003).

Apesar de a reprodução nos peixes teleósteos ser complexa, a morfologia das células germinativas e os elementos somáticos constituintes do tecido das gônadas são semelhantes nas várias espécies. Todas estas estruturas se desenvolvem no sentido de produzir gametas férteis necessários para uma reprodução bem sucedida (Hoar et al. 1983).

Os peixes constituem o grupo mais numeroso e diversificado dentro dos vertebrados e estão adaptados a diversos habitats aquáticos. Essa diversidade é refletida em suas estratégias reprodutivas e, consequentemente, na morfologia gonadal (Desjardins \& Fernald 2009).

Na maioria dos peixes teleósteos, o ovário é um órgão par que se estende no sentido crânio-caudal e se funde na região caudal, formando um ducto ovocitário comum. Contudo, podem ocorrer distinções dentre algumas espécies, em que os ovários podem se fundir ou um deles pode se degenerar e, em ambos os casos, permanecer como um órgão único (Nagahama 1983).

Histologicamente, ovários são revestidos pela túnica albugínea que emite septos para o interior do órgão formando lamelas ovulígeras que delimitam a cavidade ovariana central. Nestas lamelas se encontram ovogônias e ovócitos em diferentes fases de desenvolvimento (Bazzoli 2003).

0 reconhecimento e a caracterização das células germinativas, em seus diferentes estágios de desenvolvimento, assim como a sua distribuição e frequência nos ovários de animais adultos, permitem estimar o desenvolvimento ovariano e o tipo de desova da espécie (Lima et al. 1991).

Essas informações são de relevante interesse às pesquisas que envolvem processos reprodutivos e para a piscicultura, portanto, objetivou-se, através da observação de cortes histológicos de gônadas de M. boesemani, descrever as características das células gametogênicas durante o processo de oogênese.

\section{MATERIAL E MÉTODOS}

O experimento foi conduzido no setor de Aquicultura da Unidade de Apoio à Pesquisa em Zootecnia do Centro de Ciências e Tecnologias Agropecuárias (CCTA) da Universidade Estadual do Norte Fluminense Darcy Ribeiro (UENF), em Campos dos Goytacazes/ RJ. O processamento do material coletado (ovários) foi realizado no Laboratório de Morfologia e Patologia Animal (LMPA) do Hospital Veterinário da UENF.

Foram utilizadas, no experimento, fêmeas maduras e em atividade reprodutiva, provenientes do plantel de Melanotaenia boesemani do setor de piscicultura do LZNA/CCTA. Após a captura, os animais foram insensibilizados em água a zero grau Celsius e submetidos à eutanásia. Durante a dissecação, o ovário foi avaliado macroscopicamente quanto à forma, textura, consistência e coloração das superfícies. As gônadas foram coletadas inteiras e imediatamente fixadas em formalina neutra tamponada a $10 \%$ por um período mínimo de 24 horas.

Posteriormente, os ovários foram submetidos a processamento histológico com inclusão em parafina. Foram obtidos cortes de $5 \mu$ e as lâminas permanentes coradas em hematoxilina e eosina (HE) para análise morfométrica e morfológica dos ovários e posterior descrição das estruturas ovocitárias e das células da linhagem ovogênica, bem como dos estágios de desenvolvimento ovariano. Tais descrições foram realizadas tendo como base as descrições utilizadas por Bazzoli \& Rizzo (1990).

As fotomicrografias obtidas foram documentadas e arquivadas utilizando máquina fotográfica digital INFINITY1 e software INFINITY ANALYZE, adaptada em microscópio óptico (Nikon ${ }^{\circledR}$ ECLIPSE E2000), através do qual as células ovocitárias foram medidas para posterior análise e correlações.

Para análise estatística dos dados obtidos foi utilizado o software SAS. Os dados foram submetidos à análise de variância em nível de 5\% de significância. Em caso de diferenças, aplicou-se teste de Tukey.

\section{RESULTADOS}

O ovário de Melanotaenia boesemani foi observado como sendo um órgão único, arredondado, com coloração amarelada ocupando a parte anterior da cavidade celomática (Fig.1). Em observações realizadas antes deste experimento, foi possível verificar que o ovário, em período anterior ao reprodutivo, tem uma forma muito diminuta, o que dificulta sua observação a olho nu, no entanto, em período

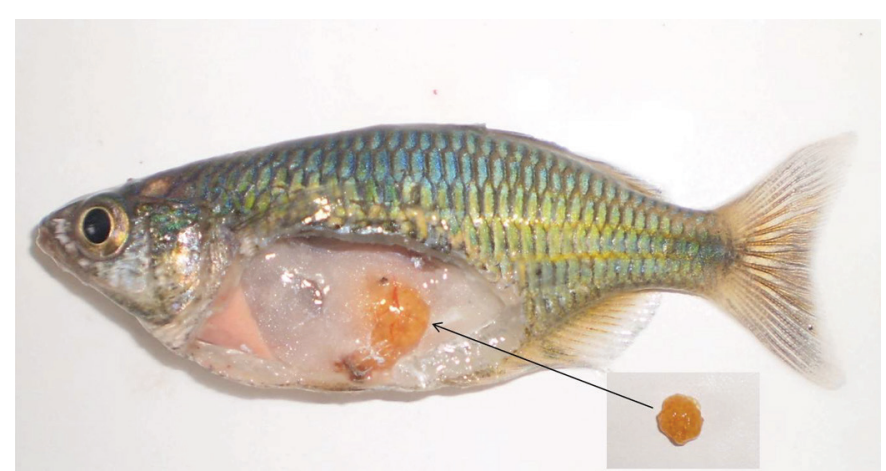

Fig.1. Localização do ovário de Melanotaenia boesemani na cavidade celomática da fêmea e detalhe do mesmo fora da cavidade demonstrando suas características macroscópicas. 
reprodutivo, apesar de não ser tão volumoso como visto em outras espécies de teleósteos, é de fácil visualização.

Este órgão estava revestido pela serosa peritoneal que o prendia à cavidade celômica e ao intestino pelo mesovário. Logo abaixo desta serosa se encontrava a albugínea ovariana, que delimita o parênquima do ovário. Esta era uma camada espessa, formada por tecido conjuntivo denso e com afinidade para a eosina. A albugínea emitia, para o interior do órgão, septos conjuntivos incompletos, as lamelas ovulígeras, que suportavam e envolviam ovogônias e ovócitos. Esta região possuía fibras conjuntivas, nervos, vasos sanguíneos, células do conjuntivo e células musculares lisas.

A organização ovariana se mostrava do tipo assincrônica. Devido ao comportamento reprodutivo intermitente da espécie, que desova várias vezes ao longo do período reprodutivo, nas observações histológicas realizadas neste estudo foi possível visualizar ovócitos em todos os estádios de desenvolvimento ovocitário (Fig.2), incluindo ovócitos em crescimento primário/jovem (01); crescimento secundário/pré vitelogênico (02); em fase de alvéolo cortical (03); e, por último, vitelogênico (04).

As ovogônias foram visualizadas em pequena quantidade e apresentavam citoplasma escasso e finamente granular, núcleo grande, ovóide e centralmente localizado com nucléolo proeminente, esférico e único.

Estatisticamente, verificou-se que durante o desenvolvimento ovocitário o diâmetro do ovócito 1 não diferia do ovócito 2 no teste de Tukey $(0,0963)$ e os demais tiveram resultado significativo com probabilidade menor que 0,0001 (Fig.3). Porém, os aspectos morfológicos de cada célula eram bastante distintos entre si.

Os ovócitos com crescimento primário (01) apresentavam citoplasma vítreo e basófilo. 0 núcleo grande e arredondado era centralizado e com nucléolos aderidos a face interna do envoltório nuclear. Nessa fase de desenvolvimento ovocitário o núcleo ocupava a maior parte do ovócito em relação ao citoplasma. Em sua maioria, os 01 eram pequenos com perímetro médio de $64,72 \pm 28,97$ micrômetros (Fig.4A).

Nos ovócitos em crescimento secundário (02) o tamanho médio foi de 112,69 $\pm 28,61$ micrômetros. 0 citoplasma ainda basófilo apresentava aspecto granular, a relação nucleoplasmática era menor que na fase anterior, embora o núcleo permaneça grande com cromatina na forma de granulações finas. A zona radiata já podia ser notada, porém de forma bastante discreta (Fig.4B).

Os ovócitos 3 foram caracterizados principalmente pela presença dos alvéolos corticais. Inicialmente, estes alvéolos, vistos como pequenos vacúolos surgiram na zona periférica do citoplasma formando uma espécie de anel e foram aumentando gradativamente em número e tamanho de acordo com o desenvolvimento da célula. Na fase final do ovócito 3 , os alvéolos corticais preenchiam quase por completo o citoplasma (Fig.4C).

O núcleo dos ovócitos 3 era inicialmente grande, de formato circular, claro, com cromatina em granulações finas e nucléolos irregulares. Com o desenvolvimento da célula, tornou-se disforme, tendo seu tamanho reduzido corando-se fortemente pela eosina. A zona radiata, ainda com pe- quena espessura, foi visualizada como uma camada com coloração fortemente eosinófila e destacada em relação ao citoplasma.

Nessa etapa, pode-se também observar a presença de estruturas filamentosas aderidas externamente à zona pelúcida com aspecto proteico, corados pela eosina (Fig.5). Esses filamentos foram identificados como estruturas de fixação que têm a função de aderir os ovos às raízes e outros substratos durante o desenvolvimento do embrião, o que é uma tática reprodutiva da espécie. Ovócitos 3 apresentaram tamanho médio de 250,93 $\pm 26,44$ micrômetros.

Os ovócitos 4 são considerados como a fase vitelogênica do desenvolvimento ovocitário. Nesse estádio, existe ainda grande presença de alvéolos corticais, porém grânulos de vitelo foram surgindo, preenchendo gradativamente o citoplasma de acordo com o desenvolvimento. Os grânulos de vitelo se coraram em tonalidade róseo-avermelhado devido à eosina e isto facilitou observar sua evolução no citoplasma do ovócito.

Com o progresso da vitelogênese nesses ovócitos, o nú-

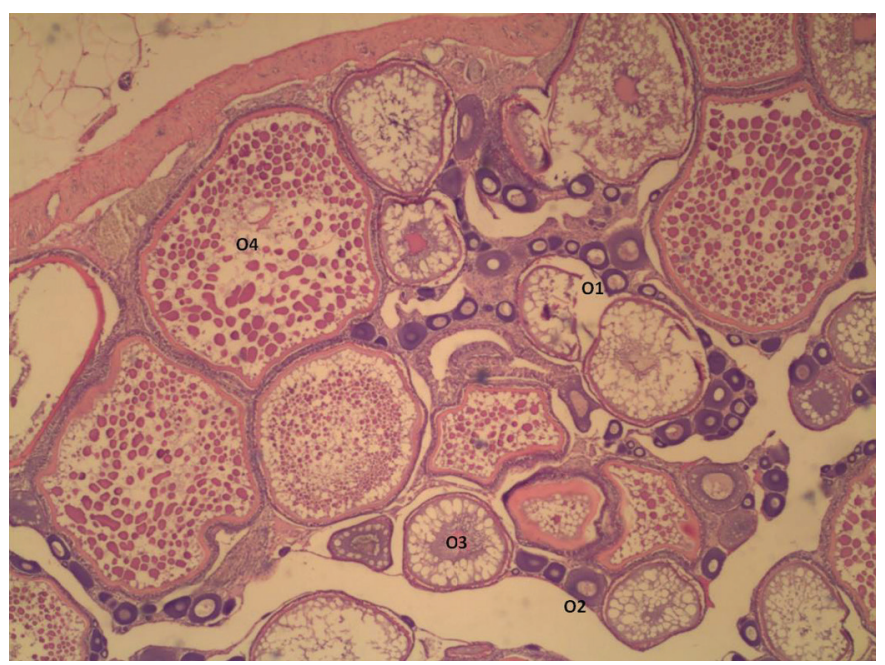

Fig.2. Lamelas ovulígeras de Melanotaenia boesemani com tipos ovocitários observados (01= ovócito 1,02 = ovócito 2,03 = ovócito 3,04 = ovócito 4). Aumento 40x.

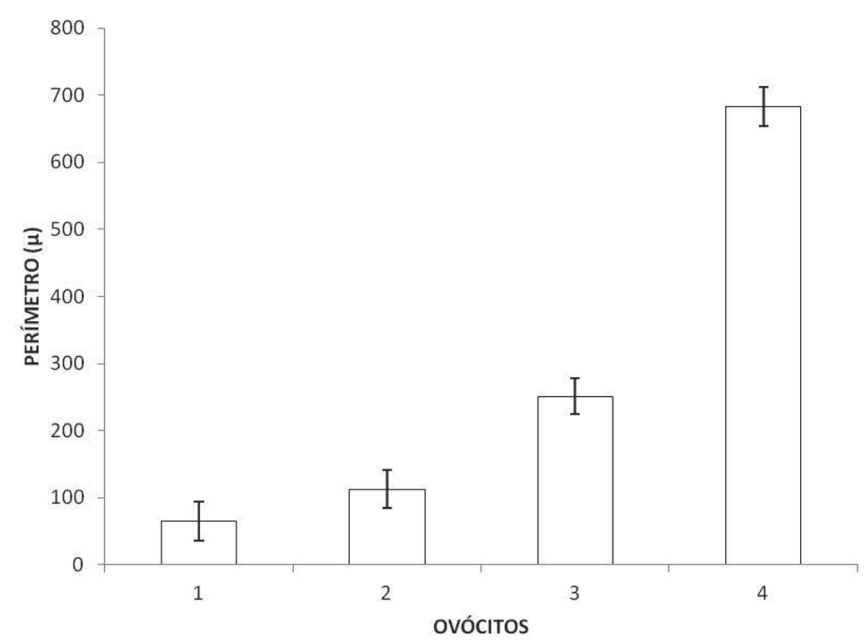

Fig.3. Valores médios do perímetro $(\mu \mathrm{m})$ dos ovócitos em diferentes fases de maturação do ovário de Melanotaenia boesemani. 

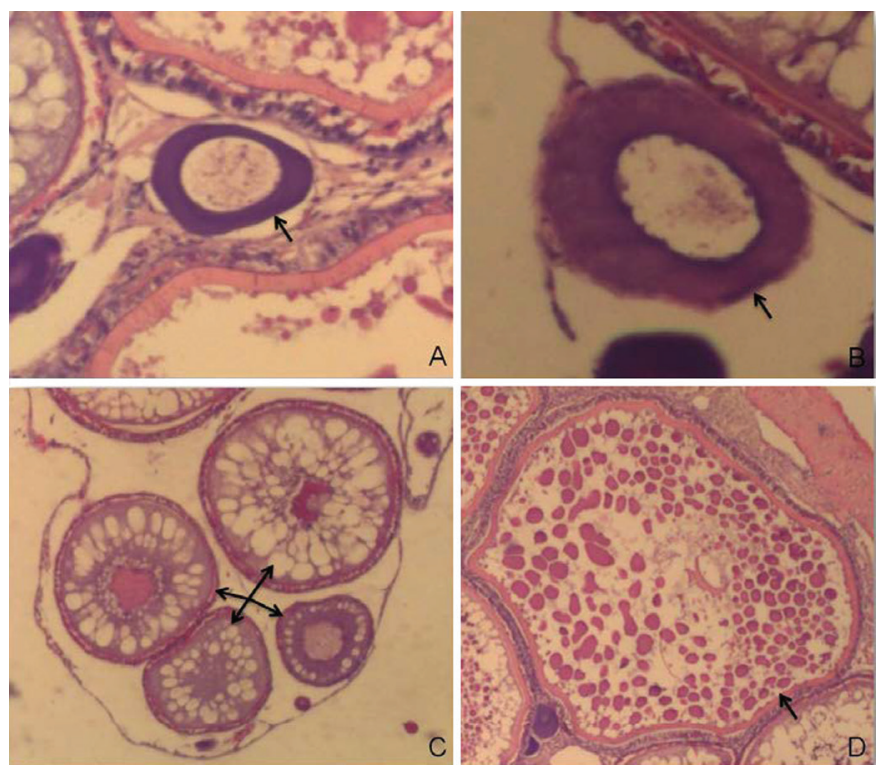

Fig.4. Tipos ovocitários de Melanotaenia boesemani, indicados pela seta. (A) Ovócito 1, (B) Ovócito 2, (C) Fases de desenvolvimento do ovócito 3, (D) Ovócito 4. Aumento 100x.

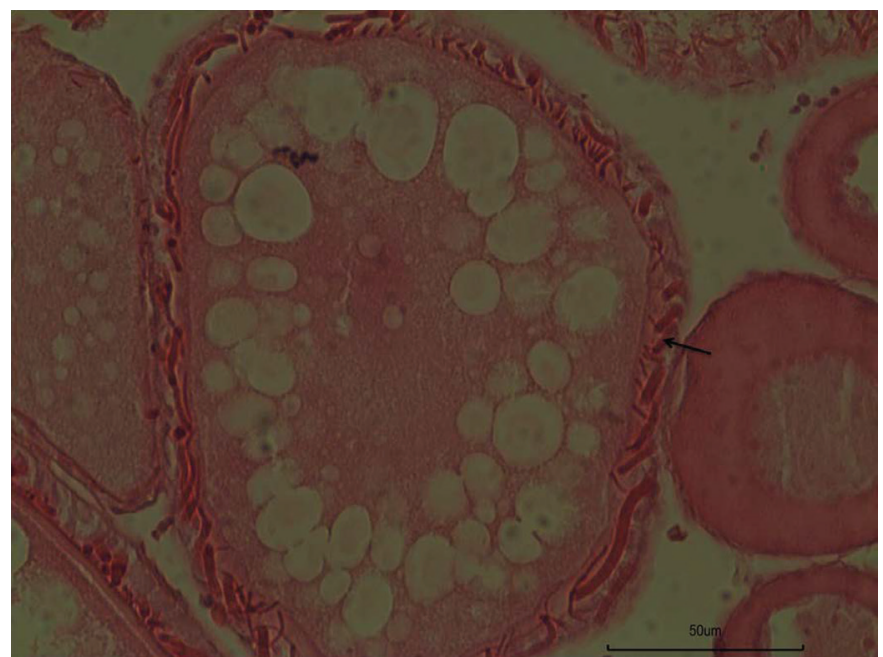

Fig.5. Filamentos de adesão corados pela eosina em ovários de Melanotaenia boesemani indicados pela seta. Aumento 400x.

mero de grânulos de vitelo aumentou e encobriu o núcleo que deixou de ser evidente. Os alvéolos corticais nesse ponto foram empurrados novamente para a periferia e os glóbulos de vitelo se fundiram, formando grandes placas que preencheram quase todo o citoplasma.

A zona radiata, nesta fase de desenvolvimento ovocitário, era mais espessa e fortemente corada pela eosina. Nela, ressaltavam-se inúmeras estrias, constituindo canalículos para possível passagem de substâncias para o interior do ovócito. Ocorreu, nessa fase também, o aumento da espessura da granulosa e presença de vacúolos por toda a camada. 0 desenvolvimento de células da teca também foi visualizado. Ovócitos 4 apresentaram tamanho médio de

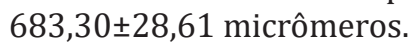

A zona pelúcida ou radiata atinge sua espessura máxima no ovócito 4, apresentando, aparentemente, uma única camada que se apresentou com estriações transversais. Em algumas dessas estriações, que, segundo a literatura, são canalículos de passagem de material, podia-se ver nitidamente um material denso percorrendo esses canais. Essa região apresentou afinidade tintorial pela eosina na coloração com HE, mostrando, portanto, coloração avermelhada.

Células foliculares da camada granulosa apresentaram formatos diferentes ao longo do ovócito. Elas estavam em contato com a zona pelúcida e com os filamentos de adesão e, no ovócito 4, elas se apresentavam como células colunares com núcleo na região apical. Seu núcleo se corou em tom azulado refletindo sua afinidade pela hematoxilina na coloração com HE.

Foi comum observar entre a camada granulosa e a zona pelúcida espaços mais claros, provocados, provavelmente, pela pressão feita pelos filamentos que se colocavam frequentemente entre a zona pelúcida e granulosa.

A teca apresentou o padrão típico encontrado em peixes teleósteos, evidenciando células e fibras conjuntivas, bem como, vasos sanguíneos.

As lâminas histológicas dos peixes estudados apresen-

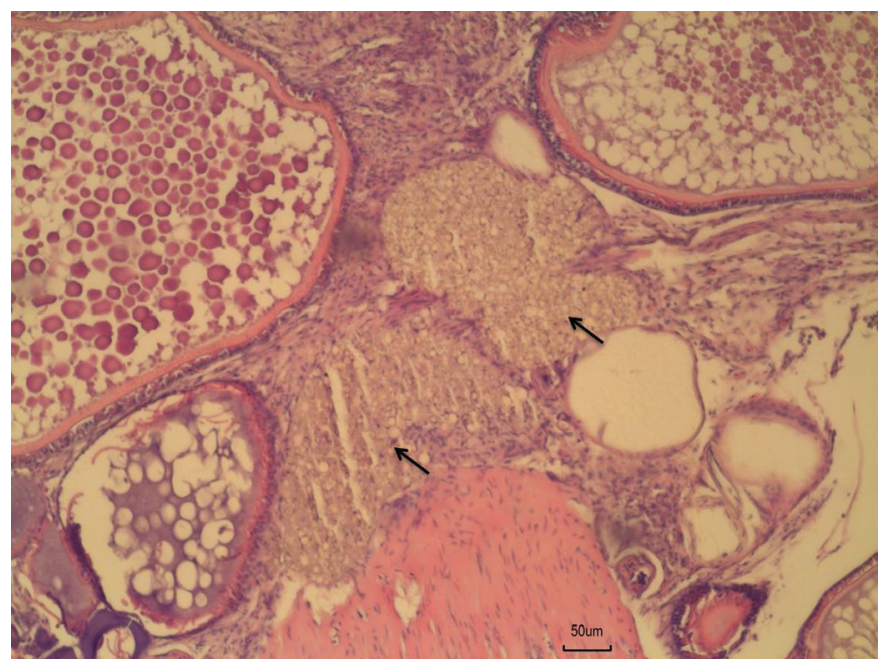

Fig.6. Marcas de desova em ovários de Melanotaenia boesemani, indicadas pela seta. Aumento 400x.

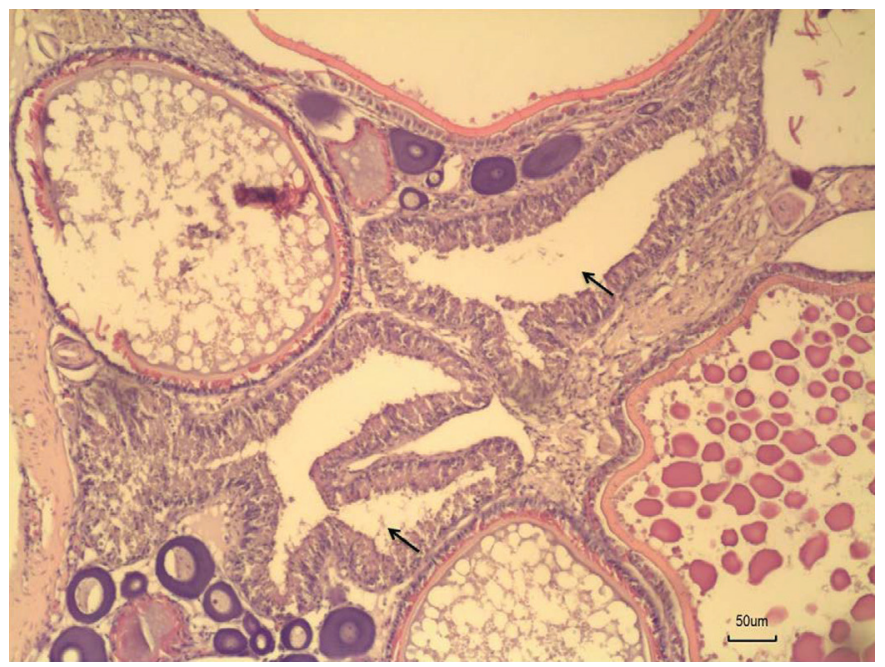

Fig.7. Folículos vazios em ovário de Melanotaenia boesemani, indicados pela seta. Aumento 400x. 
taram poucas observações de atresia ovocitária, encontradas principalmente em ovócitos 4 e apresentando o padrão clássico de eventos atrésicos na reabsorção de ovócitos.

Apesar da baixa observação de ovócitos em processo de atresia, foi possível encontrar forte evidência da mesma através da observação bastante comum de estruturas que mostravam o processo final dessas reabsorções.

Folículos vazios também foram observados com bastante frequência.

Em função do padrão de distribuição dos tipos celulares da linhagem ovocitária no ovário de $M$. boesemani, foi necessário criar uma nova denominação para o estádio de maturação ovariana que pudesse representar o momento fisiológico em que se encontravam todas as fêmeas adultas observadas no presente trabalho. Portanto, para refletir a peculiaridade de sua desova múltipla e intermitente, as fêmeas observadas foram classificadas como no estádio de maturação ovariana F3R (maduro/em reprodução).

\section{DISCUSSÃO}

A maioria dos teleósteos apresenta dois ovários dispostos no sentido crânio-caudal, fundidos na região caudal, formando o ducto ovariano comum, porém, podem ocorrer casos em que os ovários se fundem ou um deles degenera e, assim, permanecem como um único órgão (Nagahama 1983). Corroborando com essa última descrição, o ovário de $M$. boesemani apresentou-se como um órgão único, não sendo possível identificar, porém, se estes se fundiram ou se houve degeneração de um deles, mas ficou evidente que existe apenas um ovário.

A desova da referida espécie ocorre de forma parcelada e por um longo período, podendo desovar por todo o ano em condições de qualidade da água e nutrição adequadas. Portanto, o ovário após a maturidade apresenta ovócitos em todos os estádios de desenvolvimento ovocitário (Reid \& Holdway 1995). Esta situação foi observada no presente trabalho, onde, numa mesma lâmina, foi possível observar ovócitos em todos os estádios de desenvolvimento.

Comumente, o desenvolvimento ovocitário dos teleósteos, apesar de ser um processo contínuo, tem sido dividido em fases para uma melhor compreensão das alterações pelas quais passam as células germinativas (Romagosa 1991). Todavia, observa-se que existe uma divergência quanto à classificação dessas fases. Alguns pesquisadores levam em conta as características nucleares, citoplasmáticas e de vitelo; outros o tamanho; e alguns consideram os diferentes estágios de desenvolvimento dos ovócitos e as camadas de folículos ovarianos.

Em pesquisa realizada com a piracanjuba (Brycon orbgnyanus), por Ganeco et al. (2001), com piraputanga (Brycon hilarii), por Zaiden (2000) e com cascudo (Liposarcus anisitsi), por Cavalcanti (1994), a classificação adotada foi de seis fases para o desenvolvimento ovocitário: cromatinanucléolo (fase 1), perinucleolar (fase 2), alvéolo-cortical (fase 3), vitelogênico (fase 4), pós-vitelogênico/maturação final (fase 5) e atrésico (fase 6).

Em outros estudos com Pirá Conorhynchus conirostris (Ribeiro, 2002), mandi Pimelodus maculatus (Oliveira Junior 2002) e Bryconops affinis (Andrade et al. 2001) foram identificadas cinco fases: ovogônias, ovócito jovem, ovócitos pré-vitelogênicos, ovócitos com alvéolos-corticais e ovócitos vitelogênicos.

Em M. boesemani, foram caracterizados 4 estádios: englobando ovócitos em crescimento primário/jovem (01); crescimento secundário/pré vitelogênico (02); em fase de alvéolo cortical (03); e, por último, vitelogênico (04), semelhante ao utilizado por Cangussu-Mariani et al. (1991) para Astyanax bimaculatus e por Bazzoli \& Rizzo (1990) para diversas espécies estudadas.

As ovogônias de $M$. boesemani corresponderam à descrição feita para peixes teleósteos por Vazzoler (1996) e Takahashi (2006), que denominaram esta fase inicial de cromatina-nucleolar, sendo o primeiro tipo de ovócito encontrado.

Ovócitos na fase de crescimento primário seguiram o padrão descrito por Fosse Filho (2014) para Melanotaenia praecox e Amorim (2007) para Pimelodus maculatus. 0 citoplasma é pequeno em relação ao núcleo que é central, e nucléolos são facilmente visualizados na periferia do nucleoplasma. O citoplasma, inicialmente basófilo e de contorno anguloso, assemelha-se ao visualizado em Brycon orbygnyanus por Ganeco et al. (2001).

Na fase de crescimento secundário, os ovócitos apresentaram tamanho maior em relação à fase anterior, embora, em alguns momentos, o perímetro de ambos se interponha. O núcleo se manteve grande, com diversos nucléolos basófilos periféricos, mas houve diminuição da relação núcleo plasmática devido ao aumento do citoplasma.

O núcleo vitelínico, também conhecido como corpo de Balbiani, pode apresentar-se no citoplasma do ovócito como uma estrutura basófila de contorno circular e homogênea (Ganeco et al. 2001). Essa estrutura geralmente é descrita no ovócito II, mas já foi visualizada em algumas espécies no citoplasma do ovócito I (Wallace 1981, Matkovic \& Pisanó 1989). Nos ovócitos de M. boesemani, o núcleo vitelínico não se mostrou evidente em nenhum dos estádios ovocitários.

A fase de alvéolo cortical em $M$. boesemani apresentou características semelhantes ao descrito por Guraya (1986) quando cita que os alvéolos corticais aparecem primeiramente na periferia do ooplasma de onde são espalhados para o resto do ovócito e finalmente se agregam no córtex do ooplasma para constituir uma zona conspícua. Nas primeiras fases, esses ovócitos demonstraram o núcleo central, citoplasma com afinidade tintorial mudando de basófilo para acidófilo, presença de membrana pelúcida e células foliculares, assim como descrito para Brycon orbignyanus por Ganeco et al. (2001).

Menn et al. (2007) relataram que, na fase de alvéolo cortical, se inicia a inclusão de vitelogenina no citoplasma do ovócito. Semelhante ao que ocorreu com Danio rerio (Yön et al., 2008), com o avanço da fase de alvéolo cortical o núcleo dos ovócitos de $M$. boesemani se tornou disforme e com aspecto opaco, até praticamente desaparecer em meio aos alvéolos, concomitantemente, a zona radiata se tornou mais visível e espessa, assim como relatado por Jiang et al. (2010).

Na fase vitelogênica (ovócitos IV), grânulos de vitelo co- 
meçaram a se tornar evidentes em meio aos alvéolos corticais. De forma gradual, com o crescimento desses ovócitos, que foram os que apresentaram maior perímetro, o vitelo foi empurrando os alvéolos de volta à periferia, uma vez que o surgimento desses grânulos de vitelo foi visto mais frequentemente da região central para a periferia, semelhante ao descrito para Danio rerio (Çakici \& Üçuncü 2007).

Ao final do desenvolvimento, nessa fase, o ovócito possuía seu citoplasma completamente ocupado por grânulos de vitelo, assim como ocorrido em Hoplias malabaricus (Marques et al. 2000), que finalmente se fundem formando grandes placas.

O núcleo deslocado é uma característica que evidencia a proximidade de desova, porém, no presente trabalho, essa situação nuclear não foi observada, o que talvez possa ser atribuído ao fato de os grânulos de vitelo encobrirem esse aspecto nas lâminas analisadas.

Geralmente, o aparelho micropilar apresenta-se totalmente desenvolvido em ovócitos maduros. A morfologia da micrópila pode variar de acordo com a espécie, sendo caracterizados pelo menos 4 tipos (Ricardo et al. 1996). De modo geral, a micrópila é visualizada como uma pequena abertura localizada no polo animal da célula, através da qual o espermatozoide penetra no ovócito maduro (Laale 1980). Nas observações realizadas em $M$. boesemani, não foi possível evidenciar com destaque micrópila, nem aparelho micropilar.

Ovócitos atrésicos são comumente encontrados em ovários de teleósteos (Narahara 1991). O processo de atresia ovocitária pode ocorrer durante todo o ciclo reprodutivo e ocorre normalmente nos ovócitos em maturação e maduros, coincidindo com a fase de pré-desova e pós-desova (Guraya 1994). A atresia folicular envolve a atividade fagocitária dos tecidos ovarianos e boa parte dessa fagocitose é auxiliada pelas células sanguíneas que invadem o citoplasma (Mazzoni1993). A atresia envolve também a quebra da zona pelúcida e hipertrofia das células foliculares (Narahara 1991). Ovócitos com estas características foram visualizados com frequência nos ovários de $M$. boesemani e essas estruturas se apresentavam como uma massa residual pequena e com regiões amareladas resultante da reabsorção final do vitelo (grânulos de lipofuscina). Essas estruturas foram denominadas marcas de desova (Fig.6), por somente ocorrerem em peixes que apresentavam sinais de desova, ou seja, presença de folículos vazios. As marcas de desova foram visualizadas principalmente junto à cápsula conjuntiva que revestia o ovário.

Os folículos vazios (Fig.7) são formados quando o ovócito maduro é expelido da lamela para o lúmen ovariano, deixando na lamela parte de seu envoltório, ou seja, a camada granulosa formada pelas células foliculares e a teca. Essa estrutura semelhante a um colar dobrado com espaço vazio no seu interior é bem evidente no seu início, porém, aos poucos ela vai sendo absorvida pelas próprias células foliculares e por fagócitos, restando, no final desse processo, uma massa compacta residual semelhante a marca de desova, porém, mais densa e sem as granulações amareladas desta última.

Fosse Filho (2014) descreveu para Melanotaenia prae- cox estruturas filamentosas coradas pela eosina aderidas à zona pelúcida que são estruturas de fixação dos ovos para adesão aos substratos utilizados para a reprodução. Estruturas semelhantes a estas foram observados em $M$. boesemani.

A zona pelúcida surge no final do crescimento avitelogênico, inicialmente apresentando-se como camada delgada e homogênea e, quando alcança a espessura máxima, apresenta estriações conspícuas (Agostinho et al. 1982). A origem dessa camada tem sido relacionada à atividade secretora do ovócito, das células foliculares ou de ambas (Cavalcanti 1994). Essas estriações foram verificadas em $M$. boesemani e sugeridas como canais de comunicação intercelular.

Bazzoli \& Godinho (1995), estudando a ovogênese de peixes neotropicais, constataram que para $S$. hilarii a zona pelúcida possui camada dupla. Em $M$. boesemani, essa camada apresentou-se de forma simples, como uma única camada.

A definição de uma escala de maturidade é fundamental para o entendimento e para a previsão das variações de comportamento que a população, como um todo, sofre durante o ano (Cavalcanti 1994). Porém, encontra-se na literatura diversas escalas para classificação da maturidade gonadal.

Para Brycon cephalus, Zaniboni Filho \& Kawakami de Resende (1988) consideraram 5 estádios: imaturo, maturação, maduro, esvaziado e repouso, para exemplares capturados na natureza. Vazzoler (1996) por sua vez, faz uma classificação geral utilizando estádio A: imaturo, estádio B: em maturação/ repouso reprodutivo, estádio C: maduro e estádio D: esgotado. Para animais mantidos em cativeiro, Romagosa (1998) verificou os estádios de repouso, maturação, maduro e regressão. Zaiden (2000), para Brycon hilarii, considerou repouso, maturação I, maturação II, maduro e regressão. Em Piracanjuba, observaram-se 4 estádios de maturação: Repouso, Maturação Inicial, Maturação Avançada e Regressão (Ganeco et al. 2001) e Andrade et al. (2004) classificaram quatro estádios de maturação para a tabarana na represa de Três Marias: recuperação-repouso, em maturação, maduro e esgotado.

Para o presente trabalho, foram utilizadas apenas fêmeas de $M$. boesemani em atividade reprodutiva avançada e a classificação adotada para este estádio foi a de F3R (maduro/em reprodução). Tal nomenclatura foi adotada por não haver na literatura uma denominação apropriada ao tipo de desova da espécie que é intermitente e contínua. Esse fator confere ao ovário uma característica própria onde se observa a presença de todos os tipos ovocitários com incidência acentuada de ovócitos tipo IV, bem como presença de folículos vazios recentes e antigos e marcas de desova, o que caracteriza um processo contínuo de reprodução.

\section{CONCLUSÕES}

O ovário de Melanotaenia boesemani apresentou aspecto morfológico geral semelhante ao de outros peixes teleósteos e é um órgão único.

Nos ovócitos vitelogênicos deste peixe foi constatado a presença de filamentos de adesão ovocitária que se mostra- 
ram, nas lâminas histológicas, muito evidentes e ancorados na zona pelúcida.

Seu tipo de desova foi classificado como intermitente/ contínuo e o padrão de desenvolvimento de ovócitos como assincrônico.

Como nas lâminas observadas de ovário sempre foi evidente a presença de folículos vazios e marcas de desova nas lamelas ovulígeras, foi criado, para este peixe, um novo estádio de desenvolvimento ovariano, o qual denominou-se F3R (maduro/em reprodução).

Agradecimentos.- À Coordenação de Aperfeiçoamento de Pessoal de Nível Superior (CAPES) e à Universidade Estadual do Norte Fluminense Darcy Ribeiro (UENF).

\section{REFERÊNCIAS}

Agostinho A.A., Narahara M.Y. \& Godinho H.M. 1982. Morfologia dos ovários de Plecostomus commersonii (Valenciennes, 1840) Osteichtyes: Loricariidae: desenvolvimento dos ovócitos e escala de maturidade. Revta Bras. Biologia 42(1):71-77.

Allen G.R. \& Cross N.J. 1980. Descriptions of five new rainbowfishes (Melanotaeniidae) from New Guinea. Rec. West. Aust. Mus. 8(3).

Amorim J.P.A. 2007. Foliculogênese e caracterização celular das classes reprodutivas em Pimelocus maculatus (Siluriformis: Pimelodidae). Dissertação de Mestrado, Unesp-Botucatu. Editora Unesp, São Paulo.

Andrade D.R., Bazzoli N., Rizzo E. \& Sato Y. 2001. Continuos gametogenesis in the neotropical freshwater teleost, Bryconops affinis (Pisces: Characidae). Tissue \& Cell 33(5):524-532.

Andrade D.R., Godinho A.L. \& Godinho H.P. 2004. Biologia reprodutiva da tabarana Salminus hilarii (Osteichthyes, Characidae) na represa de Três Marias. Revta Bras. Ciênc. Vet. 11(3):123-128.

Bazzoli N. \& Rizzo E. 1990. A comparative cytological and cytochemical study of the oogenesis in ten Brazilian teleost fish species. Eur. Arch. Biol. 101:399-410.

Bazzoli N. \& Godinho H.P. 1995. Comparative morphology of the yolk nucleus (Balbiani's Body) in freshwater neotropical teleost fish. Revta Bras. Biologia 55(2):207-214.

Bazzoli N. 2003. Parâmetros reprodutivos de peixes de interesse comercial na região de Pirapora, p.291-306. In: Godinho H.P. \& Godinho A.L. (Eds), Águas, Peixes e Pescadores do São Francisco das Minas Gerais. PUCMinas, Belo Horizonte. 458 p.

Çakici Ö. \& Üçüncü S.I. 2007. Oocyte development in the Zebrafish, Danio rerio (Teleostei: Cyprinidae). J. Fisheries \& Aquatic Sciences 24(1/2): 137-141.

Cangussu-Mariani S.D., Rizzo E. \& Bazzoli N. 1991. Morfologia e desenvolvimento do núcleo vitelínico do lambari Astyanax bimaculatus (Linnaeus, 1758) (Osteichyhyes, Characidae). Revta Bras. Zoologia 7(3):207-213.

Cavalcanti D.G.. 1994. Reprodução do cascudo cinza Liposarcus ansisti (Holberg, 1893) (Loricariidae, Siluriforme): histologia de gônadas e fatores abióticos. Dissertação de Mestrado, Centro de Aquicultura (CAUnesp), Universidade Estadual Paulista, Jaboticabal. 124p.

Desjardins J.K. \& Fernald R.D. 2009. Fish sex: why so diverse? Curr. Opinion Neurobiol. 19(6):648-65.3.

Fishbase. Melanotaenia boesemani Allen \& Cross, 1980. Disponível em <http://www.fishbase.org/Summary/speciesSummary.php?ID=10489 \&genusname=Melanotaenia\&speciesname $=$ boesemani\&AT $=$ melanotae nia+boesemani\&lang=Portuguese> Acesso em 5 mar. 2015.

Fosse Filho J.C. 2014. Avaliação temporal da absorção dos folículos pós ovulatórios e descrição morfológica do ovário de Melanotaenia praecox (Weber \& De Beaufort, 1922). Dissertação de Mestrado, Universidade Estadual do Norte Fluminense Darcy Ribeiro, Campos dos Goytacazes, RJ.

Ganeco L.N., Nakaghi L.S.O., Urbinati E.C., Dumont Neto R. \& Vasques L.H. 2001. Análise morfológica do desenvolvimento ovocitário de piracanju- ba, Brycon orbignyanus, durante o ciclo reprodutivo. Bolm Instit. Pesca, São Paulo, 27(2):131-138.

Guraya S.S. 1986. The cell and molecular biology of fish oogenesis. Monographs in Developmental Biology 18. Karger, Basel. 213p.

Guraya S.S. 1994. Gonadal development and production of gamete in fish. Proc. Indian Natural Sci. Acad. 1:15-32.

Hoar W.S., Randall D.J. \& Brett J.R. 1983. Fish physiology, p.373-404. In:Ibid. (Eds), Reproduction. Academic Press, New York.

Humphrey C., Klumpp D.W. \& Pearson R. 2003. Early development and growth of the East rainbowfish, Melanotaenia splendida splendida (Peters). I. Morphogenesis and ontogeny. Marine and Freshwater Research 54(1):17-25.

Jiang Y.Q., Zhang T.T. \& Yang W.X. 2010. Formation of zona radiata and ultrastructural analysis of egg envelope during oogenesis of Chinese perch Siniperca chuatsi. Micron 41(1):7-14.

Kadarusman S., Paradis E. \& Pouyaud L. 2010. Description of Melanotaenia fasinensis, a new species of rainbowfish (Melanotaeniidae) from West Papua, Indonesia, with comments on the rediscovery of M. ajamaruensis and the endangered status of M. parva. Cybium 34(2):207-215.

Laale H.W. 1980. The perivilelline space and egg envelopes of bony fishes: a review. Copeia 2:210-226.

Lima R.L.V.A., Bernardino G., Val-Sella M.V., Fava de Moraes F., Schemy R.A. \& Borella M.I. 1991. Tecido germinativo ovariano e ciclo reprodutivo de pacus (Piaractus mesopotamicus Holmberg, 1887) mantidos em cativeiro. Bolm Técnico CEPTA 4(1):1-46.

Marques D.K.S., Rosa L.L. \& Gurgel H.C.B. 2000. Descrição histológica de gônadas de traíra Hoplias malabaricus (Bloch) (Osteichthyes, Erythrinidae) da barragem do rio Gramame, Alhandra, Paraíba, Brasil. Revta Bras. Zool. 17(3):573-582.

Matkovic M. \& Pisanó A. 1989. Oogenesis and ovulation in normal conditions are induced by homologous hypophysis in Hoplias malabaricus (Pisces, Erythrinidae). Revta Bras. Biol. 49(I):203-212.

Mazzoni R. 1993. Estratégia reprodutiva de duas espécies de Hypostomus Lacépède, 1803 (Osteichthyes, Loricariidae) do trecho inferior do rio Paraíba do Sul, Rio de Janeiro. Dissertação de Mestrado, Universidade Federal do Rio de Janeiro, Rio de Janeiro.

Menn L.E.F., Cerdá J. \& Babin J.P. 2007. Ultrastructural aspects of the ontogeny and differentiation of ray-finned fish ovarian follicles, p.1-38. In: Babin P.J., Cerdà J. \& Lubzens E. (Eds), The Fish Oocyte: from basic studies to biotechnological applications. Springer, New York.

Nagahama Y. 1983. Repproduction: the functional morphology of teleost gonads, p.223-275. In: Hoar W.S., Randall D.J. \& Brett J.R. (Eds), Fish Physiology. Academic Press, New York, p.223-275.

Narahara M.Y. 1991. Histologia dos ovários de teleósteos, p.39-46. 1aㅡ Semana sobre Histologia de Peixes, FACV/Unesp, Jaboticabal. (Resumos)

Oliveira Junior R.L. 2002. Análise comparativa da reprodução do mandi-amarelo, Pimelodus maculatus Lacèpéde, 1803 (Pisces, Pimelodidae), em dois trechos do rio São Francisco, MG. Dissertação de Mestrado, Universidade Federal de Minas Gerais, Belo Horizonte.

Rainbowfish 2015. Disponível em <http://rainbowfish.angfaqld.org.au/ Boesemani.htm> Acesso em 24 abr. 2015.

Reid H.P. \& Holdway D.A. 1995. Early development of the Australian crimsonspotted rainbowfish, Melanotaenia fluviatilis (Pisces: Melanotaeniidae). Marine and Freshwater Research 46(2):475-480.

Ribeiro D.C.J. 2002. Biologia reprodutiva do pirá Conorhynchus conirostris Valenciennes, 1840 (Pisces: Pimelodidae) do Rio São Francisco, região de Pirapora, Minas Gerais. Dissertação de Mestrado, Pontifícia Universidade Católica de Minas Gerais, Belo Horizonte.

Ricardo M.C.P., Aguiar C.A., Rizzo E. \& Bazzoli N. 1996. Morfologia da micrópila e da célula micropilar em teleósteos neotropicais de água doce. Arq. Bras. Med. Vet. Zootec. 48(Supl.1):17-24.

Romagosa E. 1991. Mudanças morfológicas (microscopia de luz e eletrônica) das gônadas de pacu, Piaractus mesopotamicus (Holmberg, 1887) durante o ciclo reprodutivo, em condições de confinamento. Dissertação de Mestrado, Universidade Estadual Paulista, São Paulo.

Romagosa E. 1998. Desenvolvimento gonadal (morfologia; ultraestrutura) 
e indução da reprodução do matrinxã Brycon cephalus (Günther, 1869) em cativeiro, Vale do Ribeira, São Paulo. Tese de Doutorado, Centro de Ciências Biológicas e da Saúde, Universidade Federal de São Carlos (UFSCar), São Carlos, SP. 218p.

Takahashi E.L.H. 2006. Ciclo reprodutivo da tabarana, Salminus hilarii (Valenciennes, 1849) (Characidae, Salmininae) na região do baixo Rio Sorocaba, SP. Dissertação de Mestrado, Universidade Estadual Paulista, São Paulo.

Vazzoler A.E.A.M. 1996. Biologia da reprodução de peixes teleósteos: teoria e prática. Eduem/SBI/CNPq/Nupélia, Maringá. 169 p.

Wallace R.A. \& Selman K. 1981. Cellular and dynamic aspects of oocyte growth in teleosts. Am. Zool., London, 21(1):325-343.
Yön N.D.K., Aytekin Y. \& Yüce R. 2008. Ovary maturation stages and histological investigation of ovary of the Zebrafish (Danio rerio). Braz. Archs Biol. Technol. 51(3):513-522.

Zaiden S.F. 2000. Morfologia gonadal e metabolismo energético da piraputanga Brycon hilarii (Cuvier e Valenciennes, 1849) (Pisces, Characidae) em cativeiro, durante o ciclo reprodutivo anual. Tese de Doutorado, Centro de Aquicultura, Unesp-Jaboticabal, SP. 152p.

Zaniboni-Filho E. \& Kawakami de Resende E. 1988. Anatomia de gônadas, escala de maturidade e tipo de desova do matrinxã, Brycon cephalus (Günther, 1869) (Teleostei: Characidae). Revta Bras. Biol. 48(4):833844. 